\title{
DISTRIBUCIÓN, ABUNDANCIA Y COMPOSICIÓN DEL FITOPLANCTON Y CONDICIONES AMBIENTALES EN LA CUENCA PACÍFICA COLOMBIANA, DURANTE ENERO - FEBRERO DE 2007
}

\section{DISTRIBUTION, ABUNDANCE AND COMPOSITION OF PHYTOPLANKTON AND ENVIRONMENTAL CONDITIONS IN THE COLOMBIAN PACIFIC RIVER BASIN DURING JANUARY-FEBRUARY 2007}

\author{
Edgar Arteaga Sogamoso¹, Efraín Rodríguez Rubio², Ana María Galeano³ \\ 1 Instituto de Investigaciones Marinas y Costeras “José Benito Vives de Andréis" \\ Km 17 vía Cali -Palmira, Parque Agronatura, Sede Pacífico, Valle del Cauca, Colombia \\ earteaga@invemar.org.co; edarso2001@yahoo.com \\ ${ }^{2}$ Área de Oceanografía Operacional \\ Dirección General Marítima-Centro Control Contaminación del Pacífico \\ Vía El Morro, Capitanía de Puerto de Tumaco, San Andrés de Tumaco, Nariño, Colombia \\ erodriguez@dimar.mil.co \\ ${ }^{1}$ Instituto de Investigaciones Marinas y Costeras “José Benito Vives de Andréis" \\ Km 17 vía Cali -Palmira, Parque Agronatura, Sede Pacífico, Valle del Cauca, Colombia \\ ana_galeano@invemar.org.co; anamagacha21@yahoo.com
}

Arteaga, E., Rodríguez-Rubio, E. y Galeano, A. 2008. Distribución, abundancia y composición del fitoplancton y condiciones ambientales en la cuenca pacífica colombiana, durante enero- febrero de 2007. Boletín Científico CCCP, (15): 105-122.

\begin{abstract}
RESUMEN
Se presentan los resultados de la distribución cuantitativa y cualitativa del fitoplancton enfatizado en diatomeas y dinoflagelados y las condiciones ambientales observadas en la Cuenca Pacífica Colombiana entre enero y febrero de 2007 en dos profundidades de muestreo (superficie y $50 \mathrm{~m}$ ). Se presentó predominio en abundancia de las diatomeas sobre los dinoflagelados. Los valores de abundancia en diatomeas a nivel superficial estuvieron entre 456 y 1109888 células L-1, mientras que a 50 m oscilaron entre los 740 y 143008 células L-1; para los dinoflagelados los valores estuvieron entre los 95 a 2071 células $\mathrm{L}^{-1}$ en superficie y entre 19 y 435 células $\mathrm{L}^{-1}$, para los $50 \mathrm{~m}$ de profundidad. En diatomeas, tanto superficialmente como a $50 \mathrm{~m}$ de profundidad, los taxones predominantes por su mayor abundancia y frecuencia fueron Chaetoceros, Pseudo-nitzschia, Leptocylindrus y Cylindrotheca; mientras que para los dinoflagelados lo fueron Oxytoxum y Gymnodinium. Estos resultados se dieron en condiciones ambientales que se caracterizaron por manifestar aún la presencia de la fase cálida de El Niño 2006-2007 aunque en rápida declinación, junto con características estacionales de eventos de surgencia.
\end{abstract}

Palabras clave: diatomeas, dinoflagelados, fitoplancton, surgencia, ERFEN, Pacífico colombiano, Oceanografía.

\begin{abstract}
The results of the analysis of the quantitative and qualitative distribution of the phytoplankton emphasized in diatoms and dinoflagellates and environmental conditions observed in the Colombian Pacific basin between January and February of 2007 appear, during the development of Oceanographic Cruise PACIFIC XLIV-ERFEN XLII, in 25 stations and two depths of sampling (surface and $50 \mathrm{~m}$ ) are presented. A strong predominance in abundance of the diatoms appeared over the dinoflagellates ones. The values of abundance in diatoms at surface were between 456 and 1109888 cells L $^{-1}$, whereas at $50 \mathrm{~m}$ they oscillated between the 740 and 143008 cells $\mathrm{L}^{-1}$; for dinoflagellates the values were between the 95 to 2071 cells $\mathrm{L}^{-1}$ in surface and between 19 and 435 cells $\mathrm{L}^{-1}$ for the $50 \mathrm{~m}$ depth. In diatoms, taxa predominant in abundance and frequency at both depths were Chaetoceros, Pseudo-nitzschia, Leptocylindrus and Cylindrotheca; for the dinoflagellates, taxa predominant in abundance and frequency at both depths were Oxytoxum and Gymnodinium. The environmental conditions were characterized still for the presence of the warm phase of the El Niño phenomena 2006-2007, and the seasonal characteristics related to upwelling events.
\end{abstract}

Key words: diatoms, dinoflagellates, phytoplankton, upwelling, ERFEN, Colombian Pacific, Oceanography. 


\section{INTRODUCCIÓN}

El fitoplancton marino plantea especial interés debido a su indudable importancia dentro de la red trófica al agrupar la mayor porción de productores primarios del océano (Arntz y Fharbachl, 1996; Sournia, 1978), por lo que los impactos que éste soporta, producto de variaciones físicas o biológicas del medio, repercuten sobre el resto de las comunidades que de él dependen. Por otro lado, la sensibilidad y rápida reacción ante los cambios ambientales (Ochoa y Gómez, 1997) y a la propiedad de poseer estrictos rangos en sus requerimientos abióticos y nutricionales que tienen algunos de sus representantes, lo han hecho candidato para considerarlo como indicador biológico de regiones naturales como las definidas por la latitud y de eventos oceanográficos como corrientes, giros y surgencias, entre otros (Sournia, 1978; Ochoa y Gómez, 1997; Castillo y Vizcaíno, 1992; Constain y Delgado, 1985; Balech y Ferrando, 1964 En: Antonietti et al., 1993). Es así que alteraciones ocurridas en las variables ambientales, relacionadas con la presencia del evento de El Niño, como la temperatura, salinidad y nutrientes, entre otras, tendrían incidencia sobre el fitoplancton marino (Arntz y Fharbachl, 1996; Hernández-Becerril et al. , 2007). Concordando con lo anterior y al igual que lo reportado en Chile, Perú y Ecuador (Avaria, 1984; Pesantes, 1984; Mendiola et al., 1985; Rodríguez, 2004), en Colombia también se han mencionado cambios en la comunidad fitoplanctónica relacionados con la presencia de El Niño como disminución de la biomasa fitoplanctónica, aumento en la abundancia y áreas de distribución de los dinoflagelados así como de algunas diatomeas propias de aguas cálidas y oceánicas y disminución en la abundancia y distribución de las diatomeas propias de aguas costeras (Constain y Delgado, 1985; Castillo y Vizcaíno, 1992; Medina, 1998; García, 2001); sin embargo, a pesar de los comportamientos observados hasta la fecha y teniendo en cuenta la escala temporal de El Niño aún es necesario contar con registros de datos lo suficientemente amplios para definir de manera más precisa los efectos de El Niño sobre el comportamiento del fitoplancton en la región.

El presente estudio hace parte de una serie de monitoreos que se realizan desde 1970 con el propósito de conocer, determinar y caracterizar las variaciones oceanográficas (químicas y físicas), meteorológicas y biológicas de la cuenca pacífica colombiana (CPC), los cuales han permitido obtener información concerniente al ciclo Enos (El Niño Oscilación Sur), tendientes a entender mejor sus impactos, lo que ayudaría en el futuro a establecer estrategias de pronóstico y mitigación ante las consecuencias del mismo.

Teniendo en cuenta lo anterior, el objetivo del presente trabajo es contribuir al conocimiento de las cualidades espaciales cuantitativas y cualitativas del fitoplancton marino, enfatizado en diatomeas y dinoflagelados, y describir las características ambientales observadas en la CPC entre enero y febrero de 2007, caracterizadas por la presencia del evento El Niño 2006-2007, lo que serviría como condición de referencia para la comparación con otras observaciones de este tipo en el Pacífico colombiano en la determinación de los efectos que este evento tendría sobre el fitoplancton marino.

\section{Área de Estudio}

El estudio abarcó el área de la CPC, comprendida entre los meridianos $77^{\circ} 45^{\prime} \mathrm{W}$ a $84^{\circ} \mathrm{W}$ y los paralelos $1^{\circ} 30^{\prime} \mathrm{N}$ a $5^{\circ} \mathrm{N}$, incluyendo el área triangular frente al departamento del Chocó, comprendida entre las coordenadas $5^{\circ} \mathrm{N}, 79^{\circ} 52^{\prime} \mathrm{W} ; 6^{\circ} 30^{\prime} \mathrm{N}$, $77^{\circ} 45^{\prime} \mathrm{W}$ y $5^{\circ} \mathrm{N}, 77^{\circ} 45^{\prime} \mathrm{W}$; plano sobre el cual se siguió una malla pre-establecida, conformada por 45 estaciones de muestreo. Para las estaciones biológicas los puntos distaron $30 \mathrm{mn}$ sobre el sector más costero $\left(77^{\circ} 45^{\prime} \mathrm{W}\right.$ hasta los $\left.80^{\circ} \mathrm{W}\right)$ y en 60 $\mathrm{mn}$ sobre el sector más oceánico $\left(81^{\circ} \mathrm{W}\right.$ hasta los $\left.84^{\circ} \mathrm{W}\right)$ (Fig. 1).

\section{Metodología}

Los muestreos se efectuaron entre el 24 de enero y el 19 de febrero de 2007, a bordo del buque oceanográfico ARC "Malpelo", durante el desarrollo del Crucero Pacífico XLIV-ERFEN XLII. En cada una de las 45 estaciones preestablecidas se midieron las variables oceanográficas, temperatura y salinidad, y en 25 de éstas se tomaron muestras para análisis químicos y biológicos, entre ellas las correspondientes a fitoplancton.

En las estaciones destinadas para estudios biológicos se realizaron muestreos para fitoplanc- 


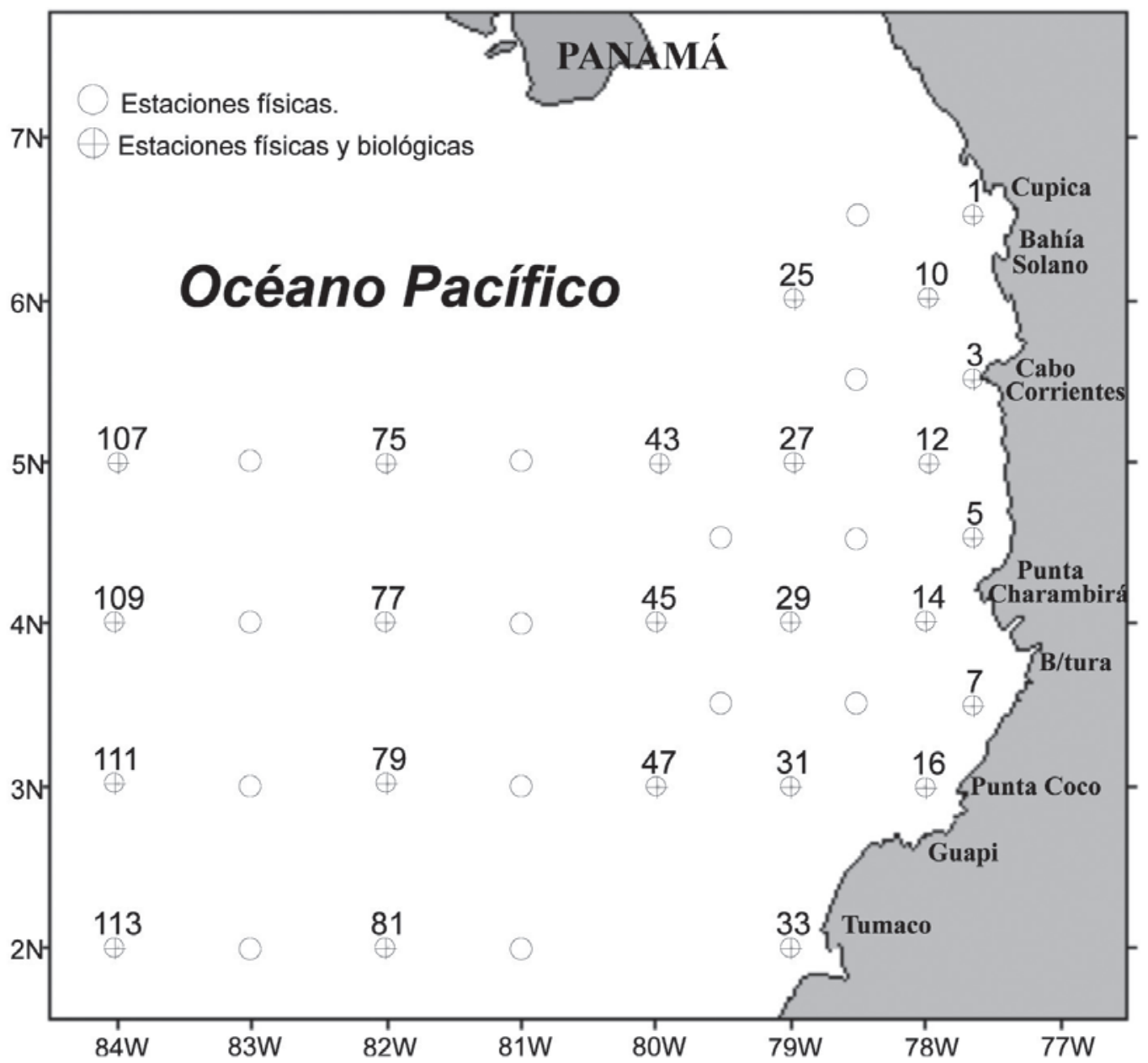

Figura 1. Área de estudio y localización de las estaciones, crucero oceanográfico Pacífico XLIV- ERFEN XLII, efectuado en el Pacífico colombiano entre enero-febrero de 2007.

ton de agua a nivel superficial $(1 \mathrm{~m})$ y a $50 \mathrm{~m}$ de profundidad con botellas Niskin de 5 L; también se recolectaron muestras mediante arrastres verticales ( 25 a $0 \mathrm{~m}$ ) con red de fitoplancton de 43 micras. Las muestras obtenidas de estos procedimientos se fijaron con formalina hasta obtener una concentración final aproximada al $5 \%$.

La determinación de la abundancia celular (células $\mathrm{L}^{-1}$ ) de las muestras de $500 \mathrm{ml}$ obtenidas con botellas Niskin se realizó mediante la técnica de Utermöhl (Villafañe y Reid, 1995; Sournia, 1978), empleando un microscopio invertido provisto de reglilla Whipple, examinando bajo éste alícuotas de $50 \mathrm{ml}$ depositadas en cámaras de sedimentación por tiempo no menor de 72 horas. Para los análisis cualitativos, las muestras obteni- das con red fueron analizadas extrayendo alícuotas depositadas en una placa de conteo Neubauer bajo microscopio óptico, examinando, identificando y contabilizando un número mínimo de 300 células. Se emplearon las guías de Cupp (1943); Thomas (1996); Soler et al., (2003); Balech (1988); Pesantes (1983); Taylor (1976), entre otros, para la identificación de organismos.

En cada estación y profundidad analizada se realizaron mediciones de salinidad y temperatura utilizando un perfilador CTD SeaBird SBE 19. Dada la naturaleza de los datos biológicos, inicialmente determinada mediante análisis de distribución de los datos (Curtosis y coeficiente de asimetría), pruebas de normalidad (Shapiro-Wilk), ensayos de transformación y homogeneidad de varianzas 
(Bartlett), se optó por el empleo de estadística no paramétrica (Mann-Whitney) para examinar la existencia de diferencias significativas entre las densidades o abundancias encontradas en las profundidades examinadas y entre los muestreos realizados de día y de noche. Para determinar el grado de correlación entre estos datos biológicos y las variables abióticas analizadas (temperatura y salinidad) se empleó el índice de correlación de Spearman.

La información tanto abiótica como biótica se organizó en forma de tablas, gráficos y mapas para permitir una mejor visualización de los resultados, con empleo de los programas Surfer 7.0 y Ocean Data View (ODV) de Schlitzer (2008).

\section{Resultados}

La temperatura superficial presentó un valor promedio de $27.7^{\circ} \mathrm{C}$, mientras que los valores mínimo y máximo fueron de 25.3 y $30{ }^{\circ} \mathrm{C}$, respectivamente, caracterizándose el costado noroccidental por mostrar los más altos valores seguidos por el nororiental, mientras que hacia la parte central se presentaron los menores registros destacándose un foco de bajas temperaturas ubicado sobre los $4^{\circ} \mathrm{N}$ y $80^{\circ} \mathrm{W}$ (Fig. 2). A $50 \mathrm{~m}$ de profundidad la temperatura superficial mínima fue de $16^{\circ} \mathrm{C}$, la máxima de $21.4^{\circ} \mathrm{C}$ con promedio de $17.5^{\circ} \mathrm{C}$; al igual que lo visto en superficie, las mayores temperaturas se observaron hacia la costa y hacia el noroccidente, mientras que las menores temperaturas fueron observadas a lo largo del eje central de la CPC, formando una lengua de agua fría con origen en la ensenada de Panamá (Figura 2).

El valor mínimo de salinidad superficial fue de 26.6, el máximo de 33.7 y el promedio de 31.8. Los mayores valores de salinidad se registraron hacia el costado suroccidental de la CPC, mientras que los menores se localizaron hacia el noroccidente y hacia la zona costera en donde se encontraron núcleos con las más bajas salinidades localizados al sur de la Bahía de Tumaco, cerca a la bahía de Buenaventura y en la región norte del Chocó (Figura 3). Para los $50 \mathrm{~m}$ de profundidad hubo un valor promedio de 34.8 , con mínimo 34.2 y máximo de 35.0 , sobresaliendo la parte suroccidental por presentar los mayores valores, los que fueron disminuyendo hacia al nororiente. Se destacó la parte noroccidental por presentar los menores valores.

Diatomeas: A nivel superficial los valores de abundancia estuvieron comprendidos entre 456 y 1109888 células $\mathrm{L}^{-1}$, con mediana de 48924 células $\mathrm{L}^{-1}$, destacándose en su orden las estaciones 045, 027, 029 y 025, por presentar los mayores registros, conteniendo más del $60 \%$ de la abundancia total (Tabla I); los mayores valores de abundancia estuvieron concentrados hacia la parte costera, la central (sobre los
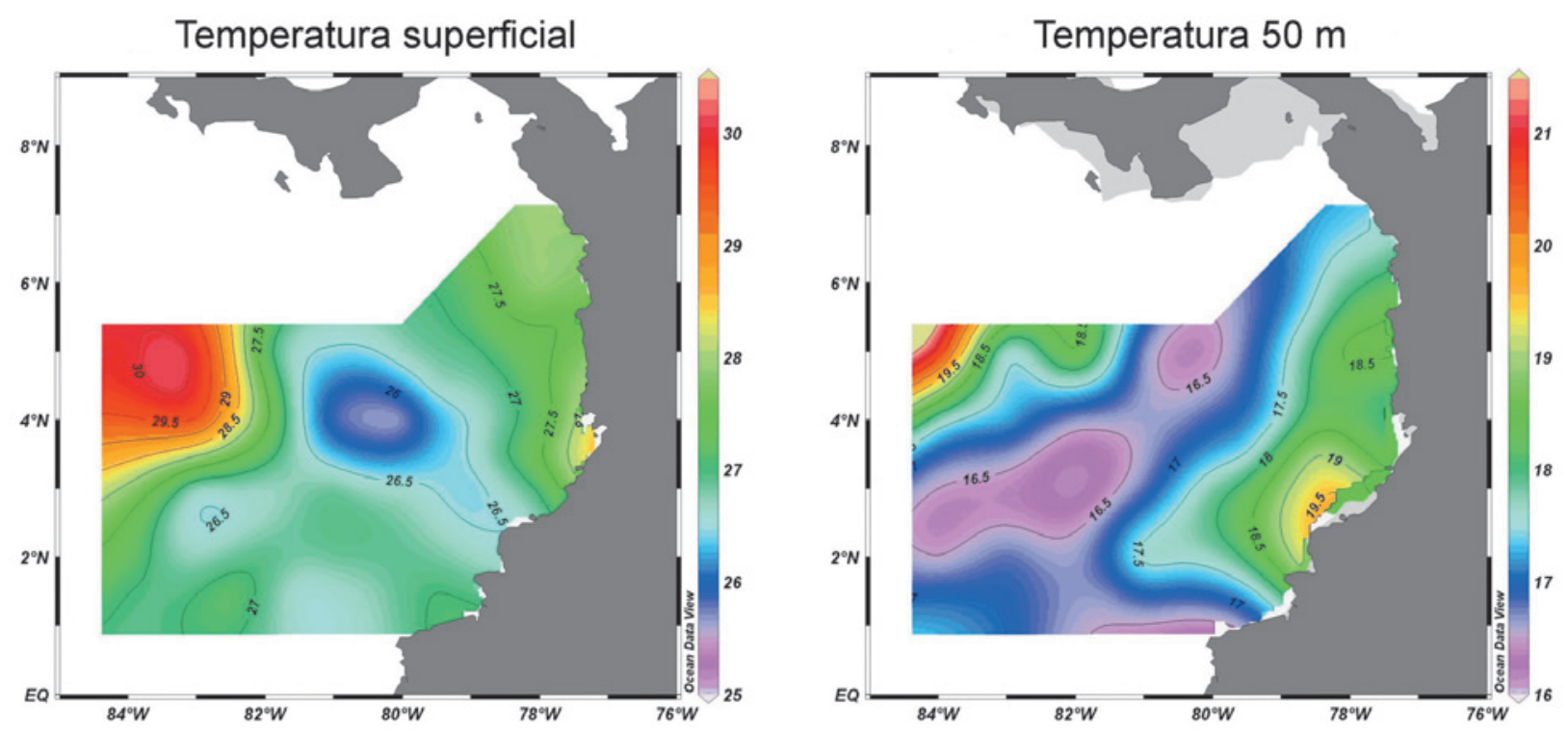

Figura 2. Distribución horizontal de la temperatura a nivel superficial y a $50 \mathrm{~m}$ de profundidad, en el Pacifico colombiano entre enero-febrero de 2007, durante el crucero oceanográfico Pacífico XLIV- ERFEN XLII. 

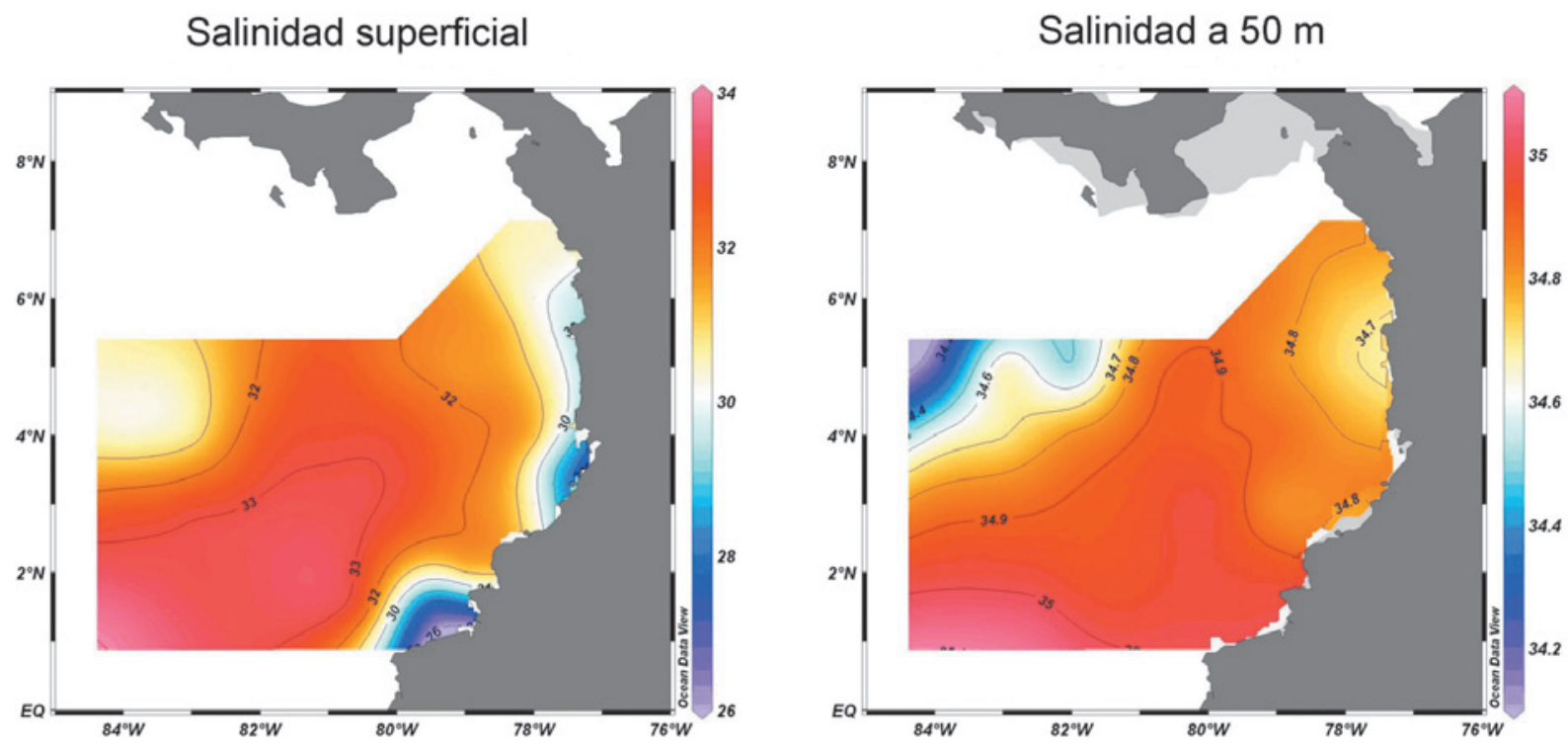

Figura 3. Distribución horizontal de la salinidad a nivel superficial y a $50 \mathrm{~m}$ de profundidad, en el Pacifico colombiano entre enerofebrero de 2007, durante el desarrollo del crucero oceanográfico Pacífico XLIV- ERFEN XLII.

meridianos 79 y $80^{\circ} \mathrm{W}$, donde se presentaron los mayores registros) y hacia el sur (frente al sector comprendido entre Punta Coco y Tumaco) del área de estudio (Figura 4). Los taxones que predominaron por su mayor abundancia fueron en su orden: Chaetoceros, Pseudo-nitzschia, Leptocylindrus, Guinardia, Hemiaulus, Dactyliosolem y Cylindrotheca, cuyos representantes compartieron más del $90 \%$ de la abundancia total (Figura 5) y por su mayor ocurrencia: Chaetoceros, Pseudo-nitzschia, Rhizosolenia, Cylindrotheca, Guinardia, Hemiaulus, Leptocylindrus y Proboscia (presentes en más del $70 \%$ de las estaciones) (Tabla II).

A $50 \mathrm{~m}$ se registraron valores de abundancia entre los 740 y 143008 células $L^{-1}$ y mediana de 3973 células $L^{-1}$, siendo en su orden las estaciones 047, 003, 107, 045 y 012 las que mostraron los mayores registros (Tabla II). La distribución tuvo un comportamiento homogéneo, destacándose la Estación 047 (localizada sobre el meridiano $80^{\circ} \mathrm{W}$, frente a Punta (oco) por presentar el mayor valor, seguida de la estación costera 003, ubicada frente a Cabo Corrientes (Figura 6); al igual que lo observado en superficie, predominaron en abundancia las células pertenecientes a los géneros Chaetoceros, Pseudonitzschia seguidos en su orden por Cylindrotheca, Hemiaulus, Thalassionema y Leptocylindrus (Figura $7)$, cuyos representantes compartieron más del $80 \%$ de la abundancia total; mientras que los Chae- toceros, Rhizosolenia, Guinardia, Leptocylindrus, Thalassionema, Bacteriastrum, Cylindrotheca y Pseudo-nitzschia estuvieron presentes en más del 70\% de las estaciones (Tabla III).

Dinoflagelados: En superficie las abundancias fluctuaron, para las estaciones en que estuvieron presentes entre 95 y 2071 células $L^{-1}$, con mediana de 388 células $\mathrm{L}^{-1}$, presentándose los mayores valores en las estaciones 029, 077, 081, 113, 047 y 079; no se detectaron en las estaciones 043 y 045 (Tabla I); se encontraron varias agrupaciones de estaciones con los mayores valores de abundancia en las estaciones 077, 079 y 081 , ubicadas sobre el meridiano $82^{\circ} \mathrm{W}$, las estaciones 029 y 047 localizadas frente al sector Punta Coco-Punta Charambirá y las estaciones más costeras frente al sector Punta Charambirá-Cupica (Figura 8). Los taxones predominantes en abundancia fueron, en su orden: Oxytoxum, Scrippsiella, Gyrodinium y Gymnodinium, que compartieron más del $80 \%$ de la abundancia total (Figura 9) y los más frecuentes: Oxytoxum, Scrippsiella y Gymnodinium (presentes en más del $70 \%$ de las estaciones) (Tabla IV).

Para los $50 \mathrm{~m}$ las estaciones 081, 033, 107, 113, 109 y 079 fueron las que en su orden registraron las mayores abundancias, estando los valores comprendidos entre 19 y 435 células $L^{-1}$, con mediana de 123 células $L^{-1}$ (Tabla I); las estaciones con las mayores abundancias estuvieron concentradas principal- 


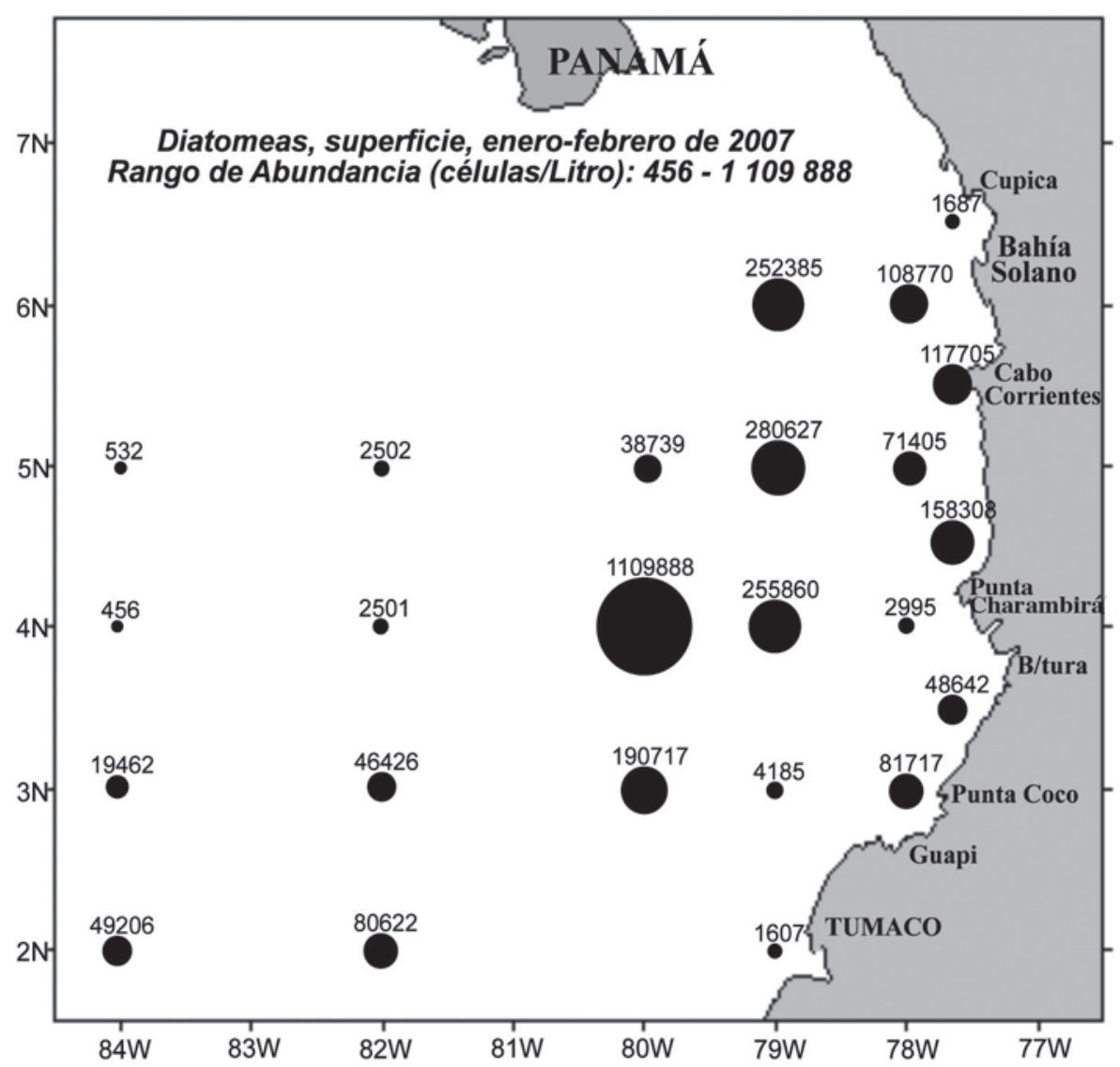

Figura 4. Distribucion horizontal de la abundancia (celulas $L^{-1}$ ) de diatomeas a nivel superficial en el Pacifico colombiano entre enero-febrero de 2007, durante el desarrollo del crucero oceanográfico Pacífico XLIV- ERFEN XLII. El tamaño de las circunferencias oscuras está en proporción al valor de abundancia encontrado.

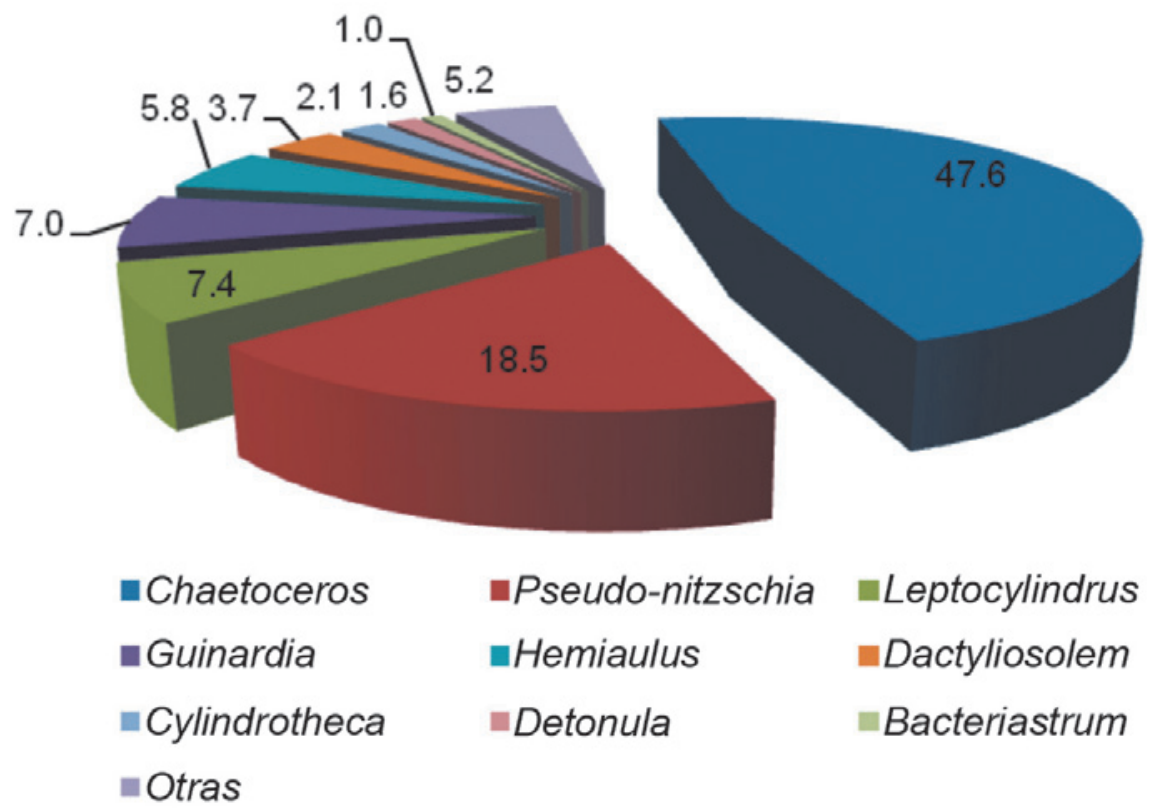

Figura 5. Composición porcentual de la comunidad de diatomeas encontradas en superficie en la CPC durante el crucero oceanográfico Pacífico XLIV- ERFEN XLII, en enero-febrero de 2007. 


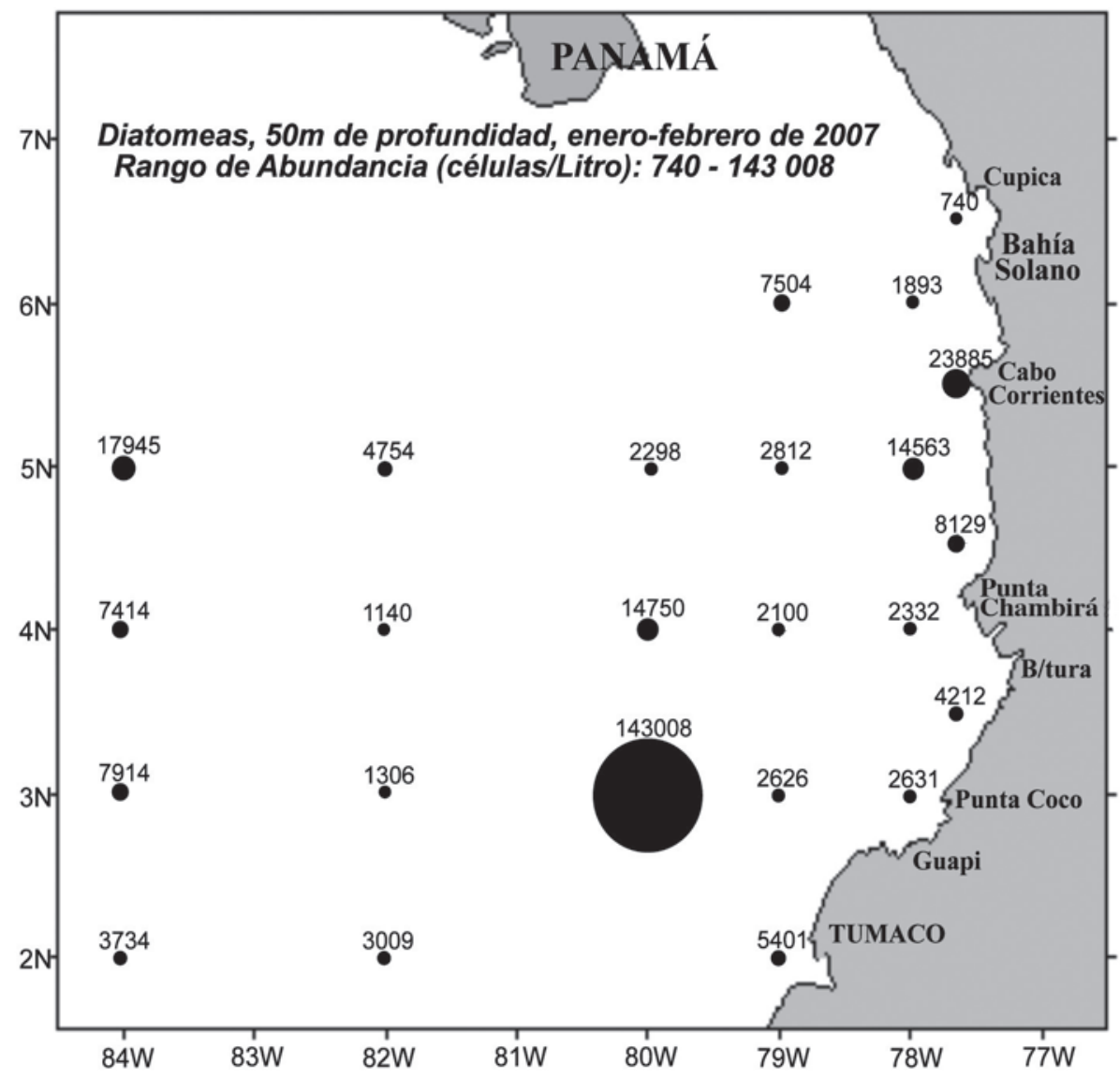

Figura 6. Distribución horizontal de la abundancia (células $\mathrm{L}^{-1}$ ) de diatomeas a $50 \mathrm{~m}$ de profundidad en el Pacífico colombiano entre enero-febrero de 2007, durante el desarrollo del crucero oceanográfico Pacífico XLIV- ERFEN XLII. El tamaño de las circunferencias oscuras está en proporción al valor de abundancia encontrado.

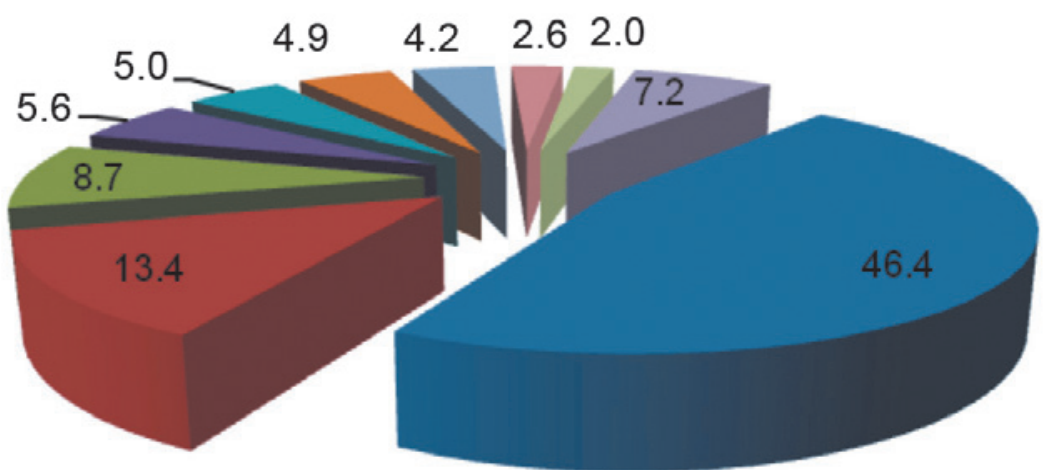

\begin{tabular}{|c|c|c|}
\hline Chaetoceros & -Pseudo-nitzschia & - Cylindrotheca \\
\hline -Hemiaulus & -Thalssionema & Leptocylindrus \\
\hline Rhizosolenia & Guinardia & Bacteriastrum \\
\hline
\end{tabular}

Figura 7. Composición porcentual de la comunidad de diatomeas encontradas a $50 \mathrm{~m}$ de profundidad en la cuenca Pacífica colombiana, durante el crucero oceanográfico Pacífico XLIV- ERFEN XLII, en enero-febrero de 2007. 
Tabla I. Ubicación de las estaciones biológicas, datos de muestreo y valores de abundancia de diatomeas y dinoflagelados en dos profundidades durante el crucero oceanográfico Pacífico XLIV - ERFEN XLII, a bordo del ARC Malpelo, entre el 24 de enero y el 19 de febrero de 2007.

\begin{tabular}{|c|c|c|c|c|c|c|c|c|}
\hline Estación & $\begin{array}{l}\text { Fecha } \\
\text { (d/m/a) }\end{array}$ & Hora & $\begin{array}{l}\text { Latitud } \\
\text { (N) }\end{array}$ & $\begin{array}{l}\text { Longitud } \\
\text { (W) }\end{array}$ & $\begin{array}{l}\text { Abundancia } \\
\text { (células/L), } \\
\text { diatomeas } \\
\text { (superficie) }\end{array}$ & $\begin{array}{c}\text { Abundancia } \\
\text { (células/L), } \\
\text { diatomeas } \\
(50 \mathrm{~m})\end{array}$ & $\begin{array}{l}\text { Abundancia } \\
\text { (células/L), } \\
\text { dinoflagelados } \\
\text { (superficie) }\end{array}$ & $\begin{array}{c}\text { Abundancia } \\
\text { (células/L), dino- } \\
\text { flagelados (50 m) }\end{array}$ \\
\hline E001 & $31 / 01 / 07$ & $10: 15$ & $06^{\circ} 30^{\prime} 00^{\prime \prime}$ & $77^{\circ} 45^{\prime} 00^{\prime \prime}$ & 1687 & 740 & 644 & 19 \\
\hline E003 & $29 / 01 / 07$ & $23: 00$ & $05^{\circ} 30^{\prime} 00^{\prime \prime}$ & $77^{\circ} 45^{\prime} 00^{\prime \prime}$ & 117704 & 23885 & 911 & 19 \\
\hline E005 & $28 / 01 / 07$ & $21: 30$ & $04^{\circ} 30^{\prime} 00^{\prime \prime}$ & $77^{\circ} 45^{\prime} 00^{\prime \prime}$ & 158308 & 8129 & 722 & 152 \\
\hline E007 & $27 / 01 / 07$ & 21:15 & $03^{\circ} 30^{\prime} 00^{\prime \prime}$ & $77^{\circ} 45^{\prime} 00^{\prime \prime}$ & 48642 & 4212 & 228 & 57 \\
\hline E010 & $30 / 01 / 07$ & 09:22 & $06^{\circ} 00^{\prime} 00^{\prime \prime}$ & $78^{\circ} 00^{\prime} 00^{\prime \prime}$ & 108770 & 1893 & 644 & 95 \\
\hline E012 & $29 / 01 / 07$ & 08:05 & $05^{\circ} 00^{\prime} 00^{\prime \prime}$ & $78^{\circ} 00^{\prime} 00^{\prime \prime}$ & 71405 & 14563 & 265 & 151 \\
\hline E014 & $28 / 01 / 07$ & $05: 50$ & $04^{\circ} 00^{\prime} 00^{\prime \prime}$ & $78^{\circ} 00^{\prime} 00^{\prime \prime}$ & 2995 & 2332 & 190 & 95 \\
\hline E016 & 27/01/07 & 08:22 & $03^{\circ} 00^{\prime} 00^{\prime \prime}$ & $78^{\circ} 00^{\prime} 00^{\prime \prime}$ & 81717 & 2631 & 114 & 38 \\
\hline E025 & 03/02/07 & 23:00 & $06^{\circ} 00^{\prime} 00^{\prime \prime}$ & $79^{\circ} 00^{\prime} 00^{\prime \prime}$ & 252385 & 7504 & 464 & 227 \\
\hline E027 & $04 / 02 / 07$ & 07:00 & $05^{\circ} 00^{\prime} 00^{\prime \prime}$ & $79^{\circ} 00^{\prime} 00^{\prime \prime}$ & 280627 & 2812 & 380 & 19 \\
\hline E029 & $08 / 02 / 07$ & $22: 30$ & $04^{\circ} 00^{\prime} 00^{\prime \prime}$ & $79^{\circ} 00^{\prime} 00^{\prime \prime}$ & 255860 & 2100 & 2071 & 19 \\
\hline E031 & $25 / 01 / 07$ & $21: 45$ & $03^{\circ} 00^{\prime} 00^{\prime \prime}$ & $79^{\circ} 00^{\prime} 00^{\prime \prime}$ & 4185 & 2626 & 95 & 76 \\
\hline E033 & $24 / 01 / 07$ & $22: 00$ & $02^{\circ} 00^{\prime} 00^{\prime \prime}$ & $79^{\circ} 00^{\prime} 00^{\prime \prime}$ & 1607 & 5401 & 397 & 379 \\
\hline E043 & $04 / 02 / 07$ & $18: 20$ & $05^{\circ} 00^{\prime} 00^{\prime \prime}$ & $80^{\circ} 00^{\prime} 00^{\prime \prime}$ & 38739 & 2298 & 0 & 209 \\
\hline E045 & $08 / 02 / 07$ & $13: 30$ & $04^{\circ} 00^{\prime} 00^{\prime \prime}$ & $80^{\circ} 00^{\prime} 00^{\prime \prime}$ & 1109888 & 14750 & 0 & 38 \\
\hline E047 & $14 / 02 / 07$ & 09:40 & $03^{\circ} 00^{\prime} 00^{\prime \prime}$ & $80^{\circ} 00^{\prime} 00^{\prime \prime}$ & 190717 & 143008 & 1061 & 227 \\
\hline E075 & 05/02/07 & 09:14 & $05^{\circ} 00^{\prime} 00^{\prime \prime}$ & $82^{\circ} 00^{\prime} 00^{\prime \prime}$ & 2502 & 4754 & 360 & 76 \\
\hline E077 & $06 / 02 / 07$ & $22: 40$ & $04^{\circ} 00^{\prime} 00^{\prime \prime}$ & $82^{\circ} 00^{\prime} 00^{\prime \prime}$ & 2501 & 1140 & 1838 & 76 \\
\hline E079 & $14 / 02 / 07$ & $23: 25$ & $03^{\circ} 00^{\prime} 00^{\prime \prime}$ & $82^{\circ} 00^{\prime} 00^{\prime \prime}$ & 46426 & 1306 & 1013 & 265 \\
\hline E081 & $16 / 02 / 07$ & $19: 47$ & $02^{\circ} 00^{\prime} 00^{\prime \prime}$ & $82^{\circ} 00^{\prime} 00^{\prime \prime}$ & 80622 & 3009 & 1457 & 435 \\
\hline E107 & 05/02/07 & 23:15 & $05^{\circ} 00^{\prime} 00^{\prime \prime}$ & $84^{\circ} 00^{\prime} 00^{\prime \prime}$ & 532 & 17945 & 228 & 341 \\
\hline E109 & 06/02/07 & 07:20 & $04^{\circ} 00^{\prime} 00^{\prime \prime}$ & $84^{\circ} 00^{\prime} 00^{\prime \prime}$ & 456 & 7414 & 209 & 266 \\
\hline E111 & $15 / 02 / 07$ & $13: 08$ & $03^{\circ} 00^{\prime} 00^{\prime \prime}$ & $84^{\circ} 00^{\prime} 00^{\prime \prime}$ & 19462 & 7914 & 358 & 208 \\
\hline E113 & $15 / 02 / 07$ & $21: 20$ & $02^{\circ} 00^{\prime} 00^{\prime \prime}$ & $84^{\circ} 00^{\prime} 00^{\prime \prime}$ & 49206 & 3734 & 1267 & 284 \\
\hline Total & & & & & 2926943 & 286101 & 14915 & 3770 \\
\hline
\end{tabular}


Tabla II. Porcentaje de abundancia y frecuencia por estación, diatomeas, superficie del 24 de enero al 19 de febrero de 2007.

\begin{tabular}{|c|c|c|c|c|}
\hline Género & $\begin{array}{l}\text { Porcentaje relativo } \\
\text { de abundancia }\end{array}$ & Puesto ocupado & $\begin{array}{c}\text { Porcentaje } \\
\text { de estaciones } \\
\text { con presencia }\end{array}$ & Puesto ocupado \\
\hline Amphora & 0.01 & 30 & 17 & 27.5 \\
\hline Asteromphalus & 0.01 & 29 & 25 & 22.5 \\
\hline Bacteriastrum & 0.99 & 10 & 54 & 14.5 \\
\hline Cerataulina & 0.87 & 12 & 67 & 10.5 \\
\hline Chaetoceros & 46.32 & 1 & 92 & 3 \\
\hline Corethron & 0.14 & 17 & 54 & 14.5 \\
\hline Coscinodiscus & 0.01 & 28 & 4 & 34 \\
\hline Cyclotella & 0.03 & 25 & 4 & 34 \\
\hline Cylindrotheca & 2.07 & 8 & 88 & 4 \\
\hline Dactyliosolem & 3.62 & 6 & 67 & 10.5 \\
\hline Detonula & 1.51 & 9 & 54 & 14.5 \\
\hline Ditylum & 0.02 & 27 & 25 & 22.5 \\
\hline Eucampia & 0.56 & 15 & 50 & 17 \\
\hline Guinardia & 6.83 & 4 & 79 & 6.5 \\
\hline Hemiaulus & 5.62 & 5 & 79 & 6.5 \\
\hline Hemidiscus & 0.00 & 35 & 4 & 34 \\
\hline Lauderia & 0.06 & 23 & 17 & 27.5 \\
\hline Leptocylindrus & 7.23 & 3 & 71 & 8.5 \\
\hline Lioloma & 0.57 & 14 & 63 & 12 \\
\hline Lithodesmium & 0.02 & 26 & 17 & 27.5 \\
\hline Melosira & 0.01 & 33 & 4 & 34 \\
\hline Meuniera & 0.00 & 34 & 8 & 31 \\
\hline Neocalyptrella & 0.01 & 31 & 17 & 27.5 \\
\hline Nitzschia & 0.91 & 11 & 25 & 22.5 \\
\hline Odontella & 0.01 & 32 & 17 & 27.5 \\
\hline Pleurosigma & 0.11 & 19 & 54 & 14.5 \\
\hline Proboscia & 0.12 & 18 & 71 & 8.5 \\
\hline Pseudonitzschia & 18.01 & 2 & 92 & 3 \\
\hline Pseudosolenia & 0.10 & 20 & 46 & 18 \\
\hline Rhizosolenia & 0.75 & 13 & 92 & 3 \\
\hline Skeletonema & 0.09 & 21 & 33 & 20 \\
\hline Stephanopyxis & 0.08 & 22 & 17 & 27.5 \\
\hline Thalassionema & 0.49 & 16 & 38 & 19 \\
\hline Thalassiosira & 0.05 & 24 & 25 & 22.5 \\
\hline Triceratum & 0.00 & 36 & 4 & 34 \\
\hline nn varios & 2.75 & 7 & 100 & 1 \\
\hline
\end{tabular}


Tabla III. Porcentaje de abundancia y frecuencia por estación, diatomeas, $50 \mathrm{~m}$ de profundidad, del 24 de enero al 19 de febrero de 2007.

\begin{tabular}{|c|c|c|c|c|}
\hline Género & $\begin{array}{l}\text { Porcentaje relativo } \\
\text { de abundancia }\end{array}$ & Puesto ocupado & $\begin{array}{l}\text { Porcentaje de estaciones con } \\
\text { presencia }\end{array}$ & Puesto ocupado \\
\hline Amphora & 0.01 & 35 & 8 & 30.5 \\
\hline Asteromphalus & 0.25 & 15 & 54 & 12 \\
\hline Azpeitia & 0.01 & 35 & 4 & 35.5 \\
\hline Bacteriastrum & 0.95 & 10 & 79 & 8 \\
\hline Cerataulina & 0.32 & 13 & 50 & 14 \\
\hline Chaetoceros & 21.77 & 2 & 100 & 1.5 \\
\hline Corethron & 0.07 & 26.5 & 33 & 20.5 \\
\hline Coscinodiscus & 0.08 & 24.5 & 17 & 25 \\
\hline Cylindrotheca & 4.07 & 4 & 79 & 8 \\
\hline Dactyliosolem & 0.25 & 15 & 38 & 17 \\
\hline Detonula & 0.39 & 11 & 33 & 20.5 \\
\hline Ditylum & 0.02 & 31.5 & 8 & 30.5 \\
\hline Eucampia & 0.24 & 17 & 38 & 17 \\
\hline Fragiliaropsis & 0.09 & 23 & 8 & 30.5 \\
\hline Gossleriella & 0.01 & 35 & 8 & 30.5 \\
\hline Guinardia & 1.24 & 9 & 83 & 5 \\
\hline Hemiaulus & 2.64 & 5 & 67 & 10 \\
\hline Hemidiscus & 0.01 & 35 & 4 & 35.5 \\
\hline Leptocylindrus & 2.28 & 7 & 83 & 5 \\
\hline Lioloma & 0.34 & 12 & 33 & 20.5 \\
\hline Neocalyptrella & 0.02 & 31.5 & 8 & 30.5 \\
\hline Nitzschia & 0.10 & 22 & 21 & 24 \\
\hline Odontella & 0.01 & 35 & 4 & 35.5 \\
\hline Planktoniella & 0.18 & 18.5 & 58 & 11 \\
\hline Pleurosigma & 0.18 & 18.5 & 38 & 17 \\
\hline Proboscia & 0.15 & 20 & 50 & 14 \\
\hline Pseudonitzschia & 6.27 & 3 & 79 & 8 \\
\hline Pseudosolenia & 0.25 & 15 & 50 & 14 \\
\hline Rhizosolenia & 1.98 & 8 & 92 & 3 \\
\hline Roperia & 0.04 & 28.5 & 13 & 26.5 \\
\hline Skeletonema & 0.07 & 26.5 & 13 & 26.5 \\
\hline Stephanopyxis & 0.03 & 30 & 8 & 30.5 \\
\hline Thalassionema & 2.32 & 6 & 83 & 5 \\
\hline Thalassiosira & 0.13 & 21 & 33 & 20.5 \\
\hline Thalassiothrix & 0.04 & 28.5 & 4 & 35.5 \\
\hline Triceratum & 0.08 & 24.5 & 25 & 23 \\
\hline$n n$ varios & 53.13 & 1 & 100 & 1.5 \\
\hline
\end{tabular}




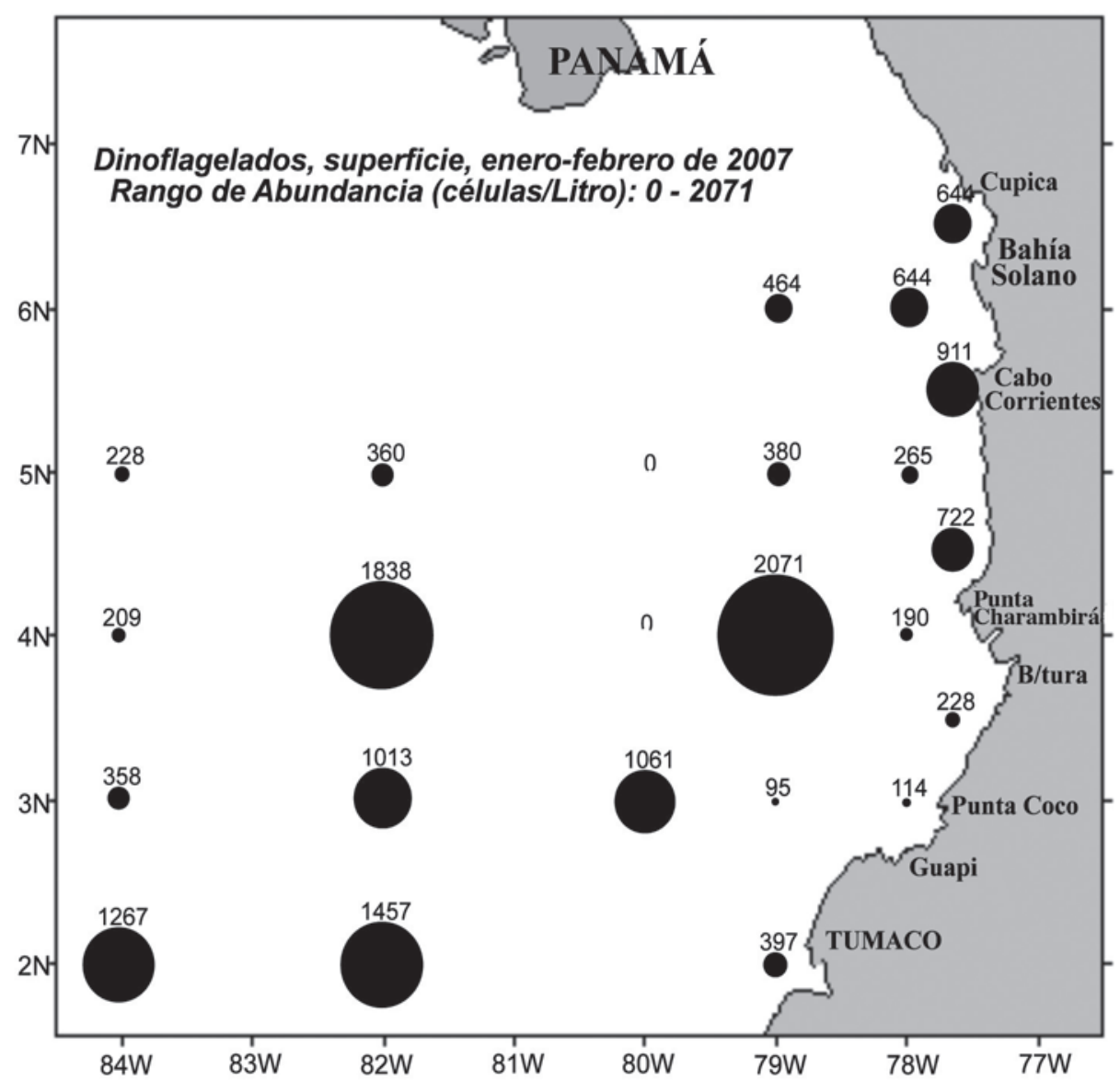

Figura 8. Distribución horizontal de la abundancia (células $\mathrm{L}^{-1}$ ) de dinoflagelados a nivel superficial en el Pacífico colombiano, entre enero-febrero de 2007, durante el desarrollo del crucero oceanográfico Pacífico XLIV- ERFEN XLII. El tamaño de las circunferencias oscuras está en proporción al valor de abundancia encontrado.

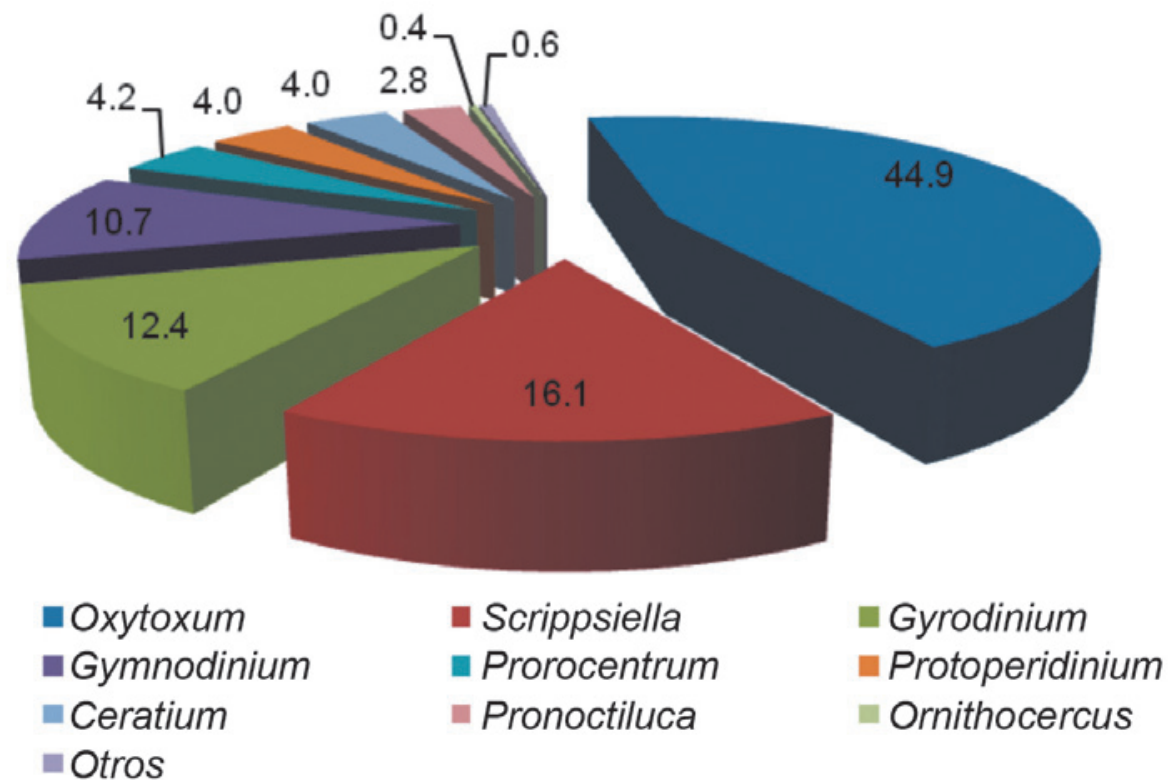

Figura 9. Composición porcentual de la comunidad de dinoflagelados encontrados en superficie en la cuenca Pacífica colombiana durante el crucero oceanográfico Pacífico XLIV- ERFEN XLII, de enero-febrero 2007. 
Tabla IV. Porcentaje de abundancia y frecuencia por estación, dinoflagelados, superficie, 24 de enero al 19 de febrero de 2007.

\begin{tabular}{lllll}
\hline Género & $\begin{array}{l}\text { Porcentaje relativo de } \\
\text { abundancia }\end{array}$ & Puesto ocupado & \multicolumn{2}{l}{$\begin{array}{l}\text { Porcentaje de estaciones } \\
\text { con presencia }\end{array}$} \\
\hline Ceratium & 4.0 & 6.5 & 55 & 5.5 \\
Ceratocorys & 0.4 & 9.5 & 9 & 9.5 \\
Gymnodinium & 10.6 & 4 & 73 & 3 \\
Gyrodinium & 12.3 & 3 & 64 & 4 \\
Ornithocercus & 0.4 & 9.5 & 9 & 9.5 \\
Oxytoxum & 44.8 & 1 & 100 & 1 \\
Podolampas & 0.3 & 11.5 & 5 & 11.5 \\
Pronoctiluca & 2.8 & 8 & 27 & 8 \\
Prorocentrum & 4.2 & 5 & 41 & 7 \\
Protoperidinium & 4.0 & 6.5 & 55 & 5.5 \\
Scrippsiella & 16.1 & 2 & 82 & 2 \\
nn varios & 0.3 & 11.5 & 5 & 11.5 \\
\hline
\end{tabular}

mente hacia el sur y al occidente del área de estudio (Figura 10); Oxytoxum, Gymnodinium, Gyrodinium, Protoperidinium y Pronoctiluca fueron los que presentaron las mayores abundancias, conllevando más del $80 \%$ de la abundancia total (Figura 11), siendo el más frecuente Oxytoxum (presente en más del $70 \%$ de las estaciones) (Tabla V).

En el análisis de las muestras obtenidas con red, se diferenciaron un total de 128 taxones, entre especies y morfotipos de diatomeas, destacándose por su mayor frecuencia Cerataulina pelagica, Proboscia alata, Rhizosolenia styliformis, Guinardia flaccida, Hemiaulus hauckii, Chaetoceros curvisetus, Ch. diversus, H. membranaceus, Leptocylindrus danicus, Pseudo-nitzschia sp, Ch. affinis, Ch. lorenzianus y Guinardia striata por estar presentes en más del $70 \%$ de las estaciones; Ch. curvisetus y $P$. alata predominaron por su abundancia relativa en el 25 y $17 \%$ de las estaciones, respectivamente. En los dinoflagelados se distinguieron un total de 72 especies y morfotipos, destacándose Protoperidinium depressum y Scrippsiella sp. por ser los más frecuentes ( 55 y $43 \%$ de las estaciones, respectivamente), predominando este último en número en los conteos por estación (en 5 de las 21 estaciones en donde se encontraron dinoflagelados).

Tanto en diatomeas como en dinoflagelados no hubo diferencias significativas en las abundancias entre las estaciones realizadas de día y de noche $(p>0.05)$ para cada una de las profundida- des analizadas. La comparación de los valores de abundancia entre las profundidades analizadas (superficial y $50 \mathrm{~m}$ ) arrojó diferencias significativas (Mann Whitney, $p<0.05$ ) para ambos grupos, con los mayores registros a nivel superficial. Los análisis de correlación entre los valores de abundancia en diatomeas y dinoflagelados y los parámetros abióticos analizados (temperatura y salinidad) para cada una de las profundidades evaluadas fueron bajos y no significativos $(p<0.05)$. No obstante, para las diatomeas encontradas en superficie se observó una correlación negativa con la temperatura y positiva para la salinidad, mientras que a $50 \mathrm{~m}$ este comportamiento fue inverso. Para los dinoflagelados, en superficie, la abundancia presentó una correlación positiva tanto para la temperatura como para la salinidad; siendo a $50 \mathrm{~m}$ negativo para la temperatura y positivo para la salinidad.

\section{DIsCusión}

Se destacó enero-febrero de 2007, período de ejecución del presente trabajo, por la presencia de dos eventos oceanográficos y climáticos que afectaron la CPC:

(i) El primero de tipo estacional y presente a principios de año, caracterizado porque la zona de confluencia intertropical (zcit) se ubica en su posición más meridional, presentándose el predominio de los vientos alisios del norte, lo que 


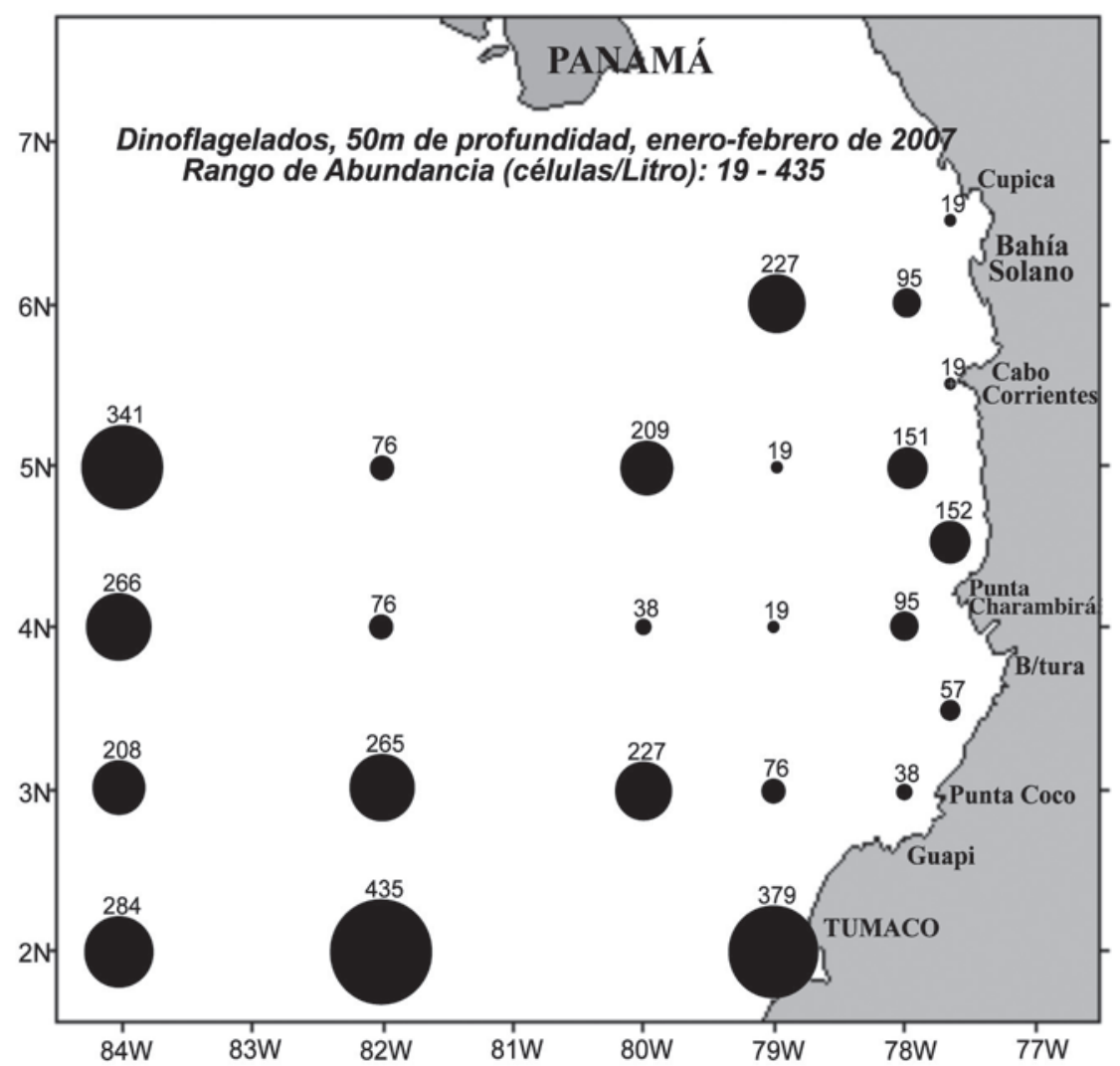

Figura 10. Distribución horizontal de la abundancia (células $\mathrm{L}^{-1}$ ) de dinoflagelados a $50 \mathrm{~m}$ de profundidad en el Pacifico colombiano entre enero-febrero de 2007, durante el desarrollo del crucero oceanográfico Pacífico XLIV- Erfen XLII. El tamaño de las circunferencias oscuras está en proporción al valor de abundancia encontrado.

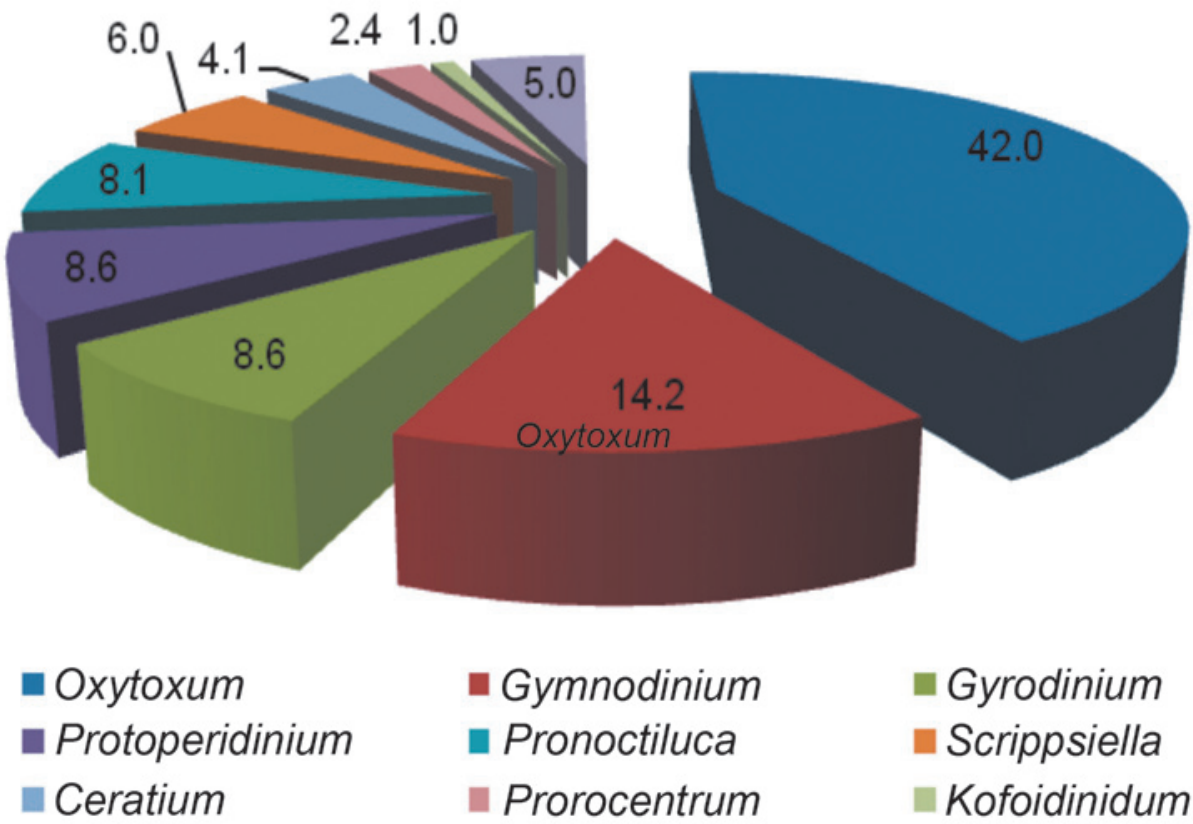

Otros

Figura 11. Composición porcentual de la comunidad de dinoflagelados encontrados a 50m de profundidad en la cuenca Pacífica colombiana durante el crucero oceanográfico Pacífico XLIV- Erfen XLII, de enero-febrero 2007. 
Tabla V. Porcentaje de abundancia y frecuencia por estación, dinoflagelados, $50 \mathrm{~m}$ de profundidad, 24 de enero al 19 de febrero de 2007.

\begin{tabular}{lccrr}
\hline \hline Género & $\begin{array}{c}\text { Porcentaje relativo de } \\
\text { abundancia }\end{array}$ & Puesto ocupado & $\begin{array}{c}\text { Porcentaje de } \\
\text { estaciones } \\
\text { con presencia }\end{array}$ & Puesto ocupado \\
\hline Alexandrium & 1.0 & 11.5 & 4.2 & 13.5 \\
Asterodinium & 1.0 & 11.5 & 4.2 & 13.5 \\
Ceratium & 4.0 & 7 & 8.3 & 8.5 \\
Goniodoma & 1.0 & 11.5 & 8.3 & 8.5 \\
Gonyaulax & 0.5 & 15.5 & 4.2 & 13.5 \\
Gymnodinium & 14.0 & 2 & 45.8 & 2 \\
Gyrodinium & 8.5 & 3.5 & 33.3 & 5 \\
Kofoidinidum & 1.0 & 11.5 & 4.2 & 13.5 \\
Oxytoxum & 41.5 & 1 & 70.8 & 1 \\
Podolampas & 1.0 & 11.5 & 8.3 & 8.5 \\
Pronoctiluca & 8.0 & 5 & 41.7 & 3.5 \\
Prorocentrum & 2.4 & 8.2 & 13.5 \\
Protoperidinium & 8.5 & 3.5 & 31.7 & 3.5 \\
\hline Pyrophacus & 0.5 & 15.5 & 4.2 & 13.5 \\
Scrippsiella & 5.9 & 6 & 20.8 & 6.5 \\
nn varios & 1.0 & 11.5 & 8.3 & 8.5 \\
\hline
\end{tabular}

permite a los vientos del noreste, conocidos en conjunto como Chorro del Viento de Panamá, pasar a través de ciertas partes del sistema montañoso del istmo de Panamá y dominar el campo de vientos de la parte norte del Panamá Bight, de la que hace parte la CPC, modelando el patrón de las corrientes marinas de esta última (Chelton et al., 2000, Rodríguez-Rubio et al., 2003, Devis-Morales et al., 2008). Es así como a principios de año (coincidente con el invierno boreal) se fortalecen los eventos de surgencia oceánica típicos para la época (Gómez y Martínez, 2005; Rodríguez-Rubio y Stuardo, 2002; Villegas, 2002) y el consecuente aporte de nutrientes de éstos, mientras que la temperatura superficial decrece y los valores de salinidad aumentan (CCCP, 2002).

(ii) El segundo evento, de tipo interanual, fue la presencia de la fase cálida de El Niño 2006-2007, que se hallaba en rápida declinación (Ciifen, 2007). En general, durante el desarrollo de un evento oceanográfico El Niño la temperatura aumenta sensiblemente en la CPC y la salinidad disminuye en las capas superiores a los 100 m (CCCP, 2002). Asimismo, el CCCP (2007) determinó, durante el desarrollo de este crucero, el calentamiento del océano por encima de los valores históricos, siendo notorio en la zona norte del Chocó y al occidente de Isla Malpelo, como consecuencia de El Niño y el desarrollo del Jet del Viento de Panamá, que disminuyó la temperatura superficial del agua en la zona central de la CPC, producto del proceso de surgencia oceánica. Sin embargo, aunque el Jet contribuyó a disminuir el calentamiento provocado por la acción de El Niño, las temperaturas estuvieron por encima de los valores históricos, lo que sugiere una disminución en la intensidad de la surgencia.

Como características biológicas a destacar en los resultados del presente estudio cabe señalar el marcado predominio en número de taxones y en abundancia que mantuvieron las diatomeas respecto a los dinoflagelados, tanto en superficie como a 50 $\mathrm{m}$ de profundidad (>98.7 \%) (Tabla II), a pesar de estar presente una condición El Niño, siendo este comportamiento diferente a lo observado por varios autores (Avaria 1984; Mendiola et al., 1985; Constain y Delgado, 1985; Castillo y Vizcaíno, 1992; Medina, 1998) en el que los dinoflagelados tendieron a ser predominantes o por lo menos más notorios durante condiciones El Niño. 
Esta diferencia obedecería a varias razones:

1) Para el caso de los trabajos ejecutados en la CPC por Constaín y Delgado (1985), Castillo y Vizcaíno (1992) y Medina (1998) a la diferencia en la época en que se realizaron los muestreos en estos trabajos (a mediados y final de año) con respecto a la del presente estudio (a principios de año), en el cual las condiciones ambientales estacionales antes mencionadas, crearían condiciones de surgencia más propicias para el desarrollo de las diatomeas (Santander et al., 2003) que para los dinoflagelados, atenuándose también de paso los efectos causados por la condición El Niño, que por lo demás se encontraba en rápida declinación.

2) La diferencia metodológica para la obtención de las muestras tendría una posible influencia en los resultados, si se tiene en cuenta que en los trabajos realizados por Constaín y Delgado (1985) y Castillo y Vizcaíno (1992) las muestras se obtuvieron mediante red, que no permite la captura eficiente de diatomeas pequeñas o de forma pennada, llevando a una subestimación de éstas con respecto a los dinoflagelados, como pudo haber sucedido con ejemplares del género Pseudo-nitzschia, los cuales fueron muy abundantes en este estudio.

3) A las diferencias en la intensidad en que se presentaron los eventos El Niño, si se tiene en cuenta que los trabajos de Constaín y Delgado (1985), Castillo y Vizcaíno (1992) y Medina (1998) se ejecutaron durante los eventos El Niño considerados como los más fuertes del siglo pasado, se debe que El Niño observado (considerado como débil a moderado) quizás no alcanzó a tener el impacto que se observó en los trabajos mencionados.

Dentro de las diatomeas se destacaron Chaetoceros, Pseudo-nitzschia, Leptocylindrus y Cylindrotheca por su mayor predominio en abundancia y frecuencia respecto a los demás taxones encontrados para las dos profundidades estudiadas (superficie y $50 \mathrm{~m}$ de profundidad), mientras que entre los dinoflagelados lo fueron Oxytoxum y Gymnodinium. Entre estos destaca la abundancia y frecuencia de Chaetoceros curvisetus y de las especies del género Pseudo-nitzschia, lo que favorecería la idea sobre la presencia de condiciones de surgencia que se dieron en el área de estudio para esta época, si se tiene en cuenta que el primero ha sido considerado como indicador de este evento (Tapia y Torres-Zambrano, 2000) y el segundo ha sido asociado con la presencia de altas concentraciones de nutrientes como lo que generalmente ocurre en zonas de surgencia (QuijanoScheggia et al., 2008 y Anderson et al., 2006, Lange et al., 1994 en Hernández-Becerril et al., 2007). Con respecto a Pseudonitzschia, es conveniente también destacar que ha sido implicado como potencial causante de floraciones tóxicas (Sar et al., 2002).

Concordando con las observaciones de Ramírez y Giraldo (2006), realizadas también en el área de estudio, la ausencia de diferencias significativas encontradas en las abundancias entre las estaciones realizadas de día y de noche pondría en duda la existencia de algún tipo de migración nictimeral por parte de estos dos grupos de organismos dentro de la columna de agua, lo que es atribuido a su limitada capacidad de desplazamiento para realizar este tipo de migraciones. Respecto a las diferencias significativas encontradas para ambos grupos en las abundancias entre las muestras obtenidas en superficie y a 50 metros de profundidad, con las mayores abundancias hacia aguas superficiales, implicaría que podría deberse a múltiples factores que favorecerían la presencia de estos organismos en esta capa (mayor disponibilidad de luz, profundidad de la termoclina, procesos hidrológicos, rangos de temperatura y salinidad, entre otros).

Los bajos valores de correlación hallados en las abundancias de las diatomeas y los dinoflagelados con las variables temperatura y salinidad parece indicar que la abundancia de estos organismos estaría influenciada también por otros factores de tipo tanto abiótico como biótico, tales como disponibilidad de nutrientes, transporte por corrientes, disponibilidad de luz, competencia, entre otros. Sin embargo, a pesar de lo anterior se observaron ciertas tendencias en la distribución en las abundancias de las diatomeas con respecto a la temperatura, en superficie, como la ubicación de las estaciones con mayor abundancia hacia el centro y sur de la CPC, donde se registraron las menores temperaturas de la zona. Es así como la localización (sobre el meridiano $80^{\circ} \mathrm{W}$ y la latitud $4^{\circ} \mathrm{N}$ ) de la estación 045 , que registró las mayores abundancias (Figura 4), coincidió con la del núcleo en donde se registraron los menores valores de temperatura para el área (Figura 2), lo que pudo indicar la presencia de condiciones de surgencia en esta estación y en general en el centro de la CPC favoreciendo el desarrollo de éstas. Lo anterior estaría soportado con lo expuesto por Villegas (2002) quien ha encontrado para febrero cinco focos de surgencia, entre los cuales uno se 
ubica precisamente sobre el meridiano $80^{\circ} \mathrm{W}$ y la latitud $4^{\circ} \mathrm{N}$, Villegas (2002) y Rodríguez-Rubio et al., (2003), además sugieren que durante los primeros meses del año (febrero-abril) la zona de surgencia es la más extensa e intensa del año para la CPC.

Por su parte y para ambas profundidades, los dinoflagelados tendieron a registrar los mayores valores de abundancia hacia el suroccidente del área de estudio, especialmente notorio a los $50 \mathrm{~m}$ de profundidad (Figuras 8 y 10), donde en general se encontraron los mayores valores de salinidad (Figura 3), ajustándose también a la tendencia encontrada con el análisis de Spearman, respecto a la correlación positiva de la abundancia de estos organismos con la salinidad.

\section{Conclusiones}

El predominio en abundancia de diatomeas sobre los dinoflagelados, pese a presentarse aún una condición Niño, está aparentemente asociada con la presencia de las características estacionales de surgencia propias para la época en el área de estudio que contrarrestó los efectos de El Niño 2006-2007 y favoreció a estos organismos.

Por otro lado, no se observaron diferencias significativas en los valores de abundancia entre las estaciones realizadas en el día y en la noche, lo que se atribuye a la limitada capacidad de desplazamiento que tienen estos organismos para ejecutar migraciones a lo largo de la columna de agua.

Los mayores valores de abundancia en diatomeas coincidieron con las zonas en donde se registraron los menores valores de temperatura para el área, asociadas a zonas de surgencia oceánica, mientras que los dinoflagelados proliferaron donde se encontraron los mayores registros de salinidad.

En diatomeas, tanto a nivel superficial como a $50 \mathrm{~m}$ de profundidad, los taxones predominantes por su abundancia y frecuencia fueron: Chaetoceros, Pseudosnitzschia,Leptocylindrus y Cylindrotheca; mientras que para los dinoflagelados los más abundantes y frecuentes fueron: Oxytoxum y Gymnodinium.

\section{AgradeCIMENTOS}

Los autores desean expresar su agradecimiento a la Armada Nacional de Colombia, a la Dirección
General Marítima (Dimar), al Centro Control Contaminación del Pacífico (CCCP) y al Instituto de Investigaciones Marinas y Costeras “José Benito Vives de Andréis" (Invemar), por el apoyo financiero y logístico brindado en la realización del crucero Pacífico XLIV-ERFEN XLII y para el procesamiento y análisis de las muestras.

Se hacen extensivos los agradecimientos al comandante del buque oceanográfico ARC “Malpelo" y su tripulación, por su apoyo en la fase de campo en desarrollo del presente estudio.

\section{Literatura Citada}

Anderson C., Brzezinski, M., Washburn, L. y Kudela, R. 2006. Circulation and environmental conditions during a toxigenic Pseudo-Nitzschia australis bloom in the Santa Barbara Channel, California. Mar Ecol Prog Ser. 327: 119-133.

Antonietti, E., Villanueva, P., Delgado, E., y Chang, F.1993. Organismos indicadores: dinoflagelados indicadores de El Niño 1991-1992. Boletín Erfen. Comisión Permanente del Pacífico Sur. Chile. (1): 20-22 p.

Arntz, W., y Fahrbach, E. 1996. El Niño, experimento climático de la naturaleza. México: Fondo de Cultura Económica. 312 pp.

Avaria, S. 1984. Cambios en la composición y biomasa del fitoplancton marino del norte de Chile durante el fenómeno EL Niño 1982-1983. Rev. Com. Perm. Pacif. Sur. 15: 303-309.

Balech. 1988. Los dinoflagelados del Atlántico Sudoccidental. Publ. Espec. Inst. Esp. Oceanogr, 1:1-300.

Castillo, F., y Vizcaíno, Z. 1992. Los indicadores biológicos del fitoplancton y su relación con el Fenómeno de El Niño 1991-1992 en el Pacífico colombiano. Bol. Cient. Cioh. 12: 13-22.

Chelton, D., Freilich, M., y Esbensen, S. 2000. Satellite observations of the wind jets off the Pacific Coast of Central America. Part II: Relationships and dynamical considerations. Monthly Weather Review 128: 2019-2043.

Constain, L., y Delgado, L. 1985. Dinoflagelados del Pacífico colombiano como indicadores del Fenómeno El Niño, Crucero Pacífico VIII-Erfen V, Nov.-Dic. 1982. Bogotá, 44 pp. Trabajo de grado (Biología Marina) Universidad Jorge Tadeo Lozano,

Ciifen. 2007. [En línea] Boletín Ciifen. [Consulta: febrero de 2007].http://www.ciifenint.org/index.php?option=com_content\&vi ew $=$ article $\& i d=158 \% 3$ Aboletin-ciifen-febrero-2007\&catid $=65 \% 3$ Ahistorial-de-boletinciifen\&ltemid=72\&lang=es 
Ciifen. 2007. [En línea] Continúa rápida declinación de El Niño 2006-2007. Centro Internacional para la Investigación del Fenómeno de El Niño. [Consulta: 15 de abril de 2007]. Disponible en: < http:// www.ciifen-int.org.

Centro Control Contaminación del Pacífico. 2002. Compilación oceanográfica de la Cuenca Pacífica Colombiana. (Ed.) Dimar. San Andrés de Tumaco: CCCP, Serie Publicaciones Especiales Vol. 1, 109 pp.

Centro Control Contaminación del Pacífico. 2007. El Niño y La Niña en la Cuenca Pacífica Colombiana, situación actual. http://www.CCCP.org.co/modules.php?name=News\&file $=$ article $\&$ sid $=269$.

Cupp, E. 1943. Marine plankton diatoms of the west coast of North America. University of California Press, Bulletin Scripps of institute of Oceanography 5(1): 1-138.

Devis-Morales, A., Schneider, W., Montoya-Sánchez, R., y Rodríguez-Rubio, E. 2008. Monsoon-like winds reverse oceanic circulation in the Panama Bight. Geophysical Research Letters 35 L20607: 1-6.

García, I. 2001. Efectos de los eventos El Niño y La Niña sobre las comunidades de fitoplancton al interior de la ensenada de Tumaco (Colombia). Bol. Cient. CCCP 8: 15-25.

Gómez, C. y Martínez, I. 2005. Nueva productividad biológica en el Pacífico Oriental Ecuatorial: respuesta al aporte de nutrientes de los ríos del Pacífico colombiano, surgencia costera y polvo atmosférico. Boletín de Geología 27(2):99-114.

Hernández-Becerril, D., Bravo-Sierra, E. , y Aké-Castillo, J. 2007. Phytoplankton on the western coasts of Baja California in two different seasons in 1998. Scientia Marina. 71(4): 735-743.

Medina, L., 1998. Cambios en la composición y abundancia de la comunidad microalgal del Pacífico colombiano en relación con el evento El Niño 9798. Boletín Científico CCCP No. 7: 58-66. Tumaco, Colombia.

Mendiola, B., Gómez, O., y Ochoa, N. 1985. Efectos del Fenómeno El Niño 1982-1883 sobre el fitoplancton de la costa peruana. Simp. Int. Afl. O Afr. 1: 417-433.

Ochoa, N., y Gómez, O. 1997. Dinoflagelados del mar peruano como indicadores de masas de agua durante los años 1982 a 1985. Boletín del Instituto del Mar del Perú, 16(2): 1-60.

Pesantes, F. 1983. Dinoflagelados del fitoplancton del Golfo de Guayaquil. Acta Oceanográfica del Pacífico (Inocar), Ecuador, 98 pp.

Pesantes, F. 1984. Distribución del fitoplancton durante noviembre de 1982 y de la clorofila del crucero de noviembre de 1983 (Ecuador). Rev. Com. Perm. Pacif. Sur. 15: 239-245.

Quijano-Scheggia S., Garcés, E, Flo, E., FernándezTejedor, M, Dogéne, J., y Camp, J. 2008. Bloom dynamics of the genus Pseudo-nitzschia (Bacillariophyceae) in two coastal bays (NW Mediterranean Sea). SCI. MAR., 72(3): 577-590.

Ramírez D., y Giraldo, A. 2006. Estructura comunitaria del fitoplancton de la Cuenca Pacífica Colombiana durante la campaña oceanográfica Pacífico XXXIXErfen XXXVII. Boletín Científico del CCCP 13: 65-84.

Rodríguez-Rubio, E., \& Stuardo, J. 2002. Variability of photosynthetic pigments in the Colombian Pacific Ocean and its relationship whit the wind field using ADEOS-I data. Proceedings Indian Academic Sciences (Earth Planet science), Vol 111 (3), pp. 227-236.

Rodríguez-Rubio, E., Schneider, W. y Abarca del Río, R. 2003. On the seasonal circulation within the Panama Bight derived from satellite observations of wind, altimetry and sea surface temperature. Geophysical Research Letters 30 (7), 1410.

Rodríguez, L. 2004. Observaciones sobre efectos de El Niño 1997-1998 en el fitoplancton de Bahía Antofagasta y durante un fenómeno de surgencia en Bahía Mejillones del Sur. Antofagasta, Chile. S. Avaria, J. Carrasco, J. Rutllant Y E. Yañez. (eds.). El Niño-La Niña 1997-2000. Sus efectos en Chile. Cona, Chile, Valparaíso. pp. 97-118.

Santander E., Herrera, L, y Merino, C. 2003. Fluctuación diaria del fitoplancton en la capa superficial del océano durante la primavera de 1997 en el norte de Chile (20¹8'S): II. Composición específica y abundancia celular. Revista de Biología Marina y Oceanografía, 38(1): 13-25.

Sar, A, Ferrairo, M, y Reguera, B. 2002. Floraciones algales en el Cono Sur Americano. Instituto Español de Oceanografía. España, 311 pp.

Schlitzer, R. 2008. [En línea] Ocean Data View. [Consulta: 1 de agosto de 2008]. Disponible en: < http:// www.odv.awi.de>.

Soler, A., Pérez, M. y Aguilar, E. 2003. Diatomeas de las costas del Pacífico en Panamá: estudio florístico. Universidad de Panamá: Vicerrectora de Investigación y Postgrado. Panamá, 384 pp.

Sournia, A. 1978. Phytoplankton manual. Organización de las Naciones Unidas para la Educación, la Ciencia y la Cultura (Unesco). París, 337 pp.

Tapia, M. y Torres-Zambrano, G. 2000, Variabilidad fitoplanctónica en cinco bahías, Islas Galápagos (Ecuador). Artículo presentado en el VI Congreso Nacional de Ciencias. Ambato, Ecuador.

Taylor, T. 1976. Dinoflagellates from the International Indian Ocean expedition. A report on material 
collected by the R. V. "Anton Brunn". Institute of Oceanography and Department of Botany, Canada, 227 pp.

Thomas C. (Ed). 1997. Identifying marine diatoms and dinoflagellates. Florida Marine Research Institute. Academic Press. St. Petersburg, Florida. U S A, $858 \mathrm{pp}$.

Villafañe, V. y Reid, F. 1995. Métodos de microscopía para la cuantificación del fitoplancton. En: K.
Alveal, M. Ferrario, E. de Oliveira \& E. Sar (eds). Manual de métodos ficológicos. Universidad de Concepción, Chile, 850 pp.

Villegas, N. 2002. Evolución mensual de las corrientes verticales y zonas de surgencia en la cuenca del Pacífico colombiano (CPC). Boletín Científico CCCP 9: 29-36. 